\title{
Prácticas de consumo-desecho de residuos sólidos domiciliarios en Ciudad Juárez en 2014
}

\author{
Waste disposal-consumption practices of solid \\ household waste in Juarez City in 2014 \\ Myrna Limas Hernández*
}

Universidad Autónoma de Ciudad Juárez, Ciudad Juárez, México ORCID: http://orcid.org/o0oo-0003-4355-7661

Janette Eréndira Blanco Romero**

Universidad Autónoma de Ciudad Juárez, Ciudad Juárez, México

ORCID: http://orcid.org/o0oo-0002-6533-0137

DoI: http://dx.doi.org/I0.28928/revistaiztapalapa/832017/atc4/blancoromeroje/limashernandezm

\begin{abstract}
Resumen
El objetivo principal de este artículo es explorar y dar cuenta de las prácticas de consumo-desecho (generación, separación, reciclaje) que desarrollaban residentes de Juárez en sus domicilios en 2014 con miras a sugerir estrategias que incentiven la separación de los desechos de manera diferenciada previo conocimiento de las toneladas de residuos recolectadas. La metodología atendió el diseño de una muestra para aplicar cuestionarios cuyas cédulas de registro contenían alrededor de 50 ítems. Los datos se recogieron en 2014 en seis planteles de educación básica de la zona oriente y poniente de la localidad y los participantes fueron padres y madres de familia. El total de cuestionarios validados fueron 530, con un nivel de confianza de $97 \%$. Los resultados confirmaron que la disponibilidad de las personas para separar los residuos en los domicilios sí depende, al menos, del género, el nivel de escolaridad o la zona de residencia. Por ende, las recomendaciones para establecer un programa de separación de residuos deben focalizarse y han de sujetarse a una adecuación en el servicio de recolección por tipo de residuo, oferta de incentivos o la aplicación de sanciones, entre otras medidas.

Palabras clave: Basura, gestión de residuos, ${ }_{3} \mathrm{R}$, población en Juárez, incentivos
\end{abstract}

\begin{abstract}
The main objective of this paper is to detect and realize the waste-disposal and consumption practices (generation, separation, recycling) developed by residents of Juarez City in their homes in 2014 to propose some strategies that encourage the separation of waste differently foreseeing the tons of waste collected. The methodology covered the design of a sample to apply questionnaires considering information cards with 50 items approximately. Data collection took place in 2014 in 6 elementary and junior high schools located in the east and west of the town. The participants were parents and the total number of validated questionnaires was 530 representing a confidence level of $97 \%$. The results confirmed that the availability of people to separate residues in households depends at least of gender, level of schooling or the area of residence. Therefore, the recommendations for establishing a waste separation program should be focused and, according to the participants, must be adapted to the collection service by type of waste, offering incentives or sanctions, among other alternatives.
\end{abstract}

Keywords: Waste, Solid Waste Management, ${ }_{3} \mathrm{Rs}$, Juarez population, incentives

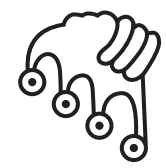

\section{IZTAPALAPA}

Agua sobre lajas

* mlimas@uacj.mx

** janetteblanco@hotmail.com 
$\mathbf{L}$ a sociedad de producción en la que operaba la economía del siglo xx establecía que el sistema debía producir sin parar y sin necesariamente importar los costos pese a la presión insostenible generada en los diferentes ecosistemas del mundo. Esa lógica incentivó que en las décadas posteriores, en lo sucesivo, se fabricaran productos con poca vida útil, objetos vacíos o con muy poco contenido, bajo estándares de "úsese poco y tírese pronto" (Sangronis, 2015), como es el caso de teléfonos móviles, alimentos, laptops, lavadoras, prendas de vestir, mp3, etcétera.

Esta situación ha generado sin duda patrones de consumo no responsable por parte de los diferentes agentes y actores involucrados (naciones, empresas y consumidores) por lo que es pertinente, en nuestra opinión, estudiar esta situación y tomar medidas que eviten, al menos, el manejo inadecuado de los residuos sólidos domiciliarios.

En esta lógica, parece adecuado partir de la idea de que el discurso del siglo XxI en materia de consumo sugiere que las poblaciones deben alimentar una cultura de apetito insaciable por las mercancías materiales que minimice la atención hacia los costos de producción (léase extracción de recursos, fabricación, distribución, etc.) y evite tomar en cuenta las consecuencias generadas en el medio ambiente (deterioro de los recursos y la generación indiscriminada de una enorme cantidad de basura a nivel mundial).

Ante ese apetito insaciable de consumo se requiere tomar conciencia de lo apuntado por De la Cruz (2008) cuando señala que el proceso de la basura, en realidad, comienza con la elaboración de cada nuevo producto fabricado para sustituir al objeto "viejo" en uso. Este juego de reemplazo de bienes demanda reconocer a priori que día con día se genera una vasta cantidad de toneladas de residuos sólidos a nivel mundial que requiere minimizarse y demanda tomar medidas que reorienten el inadecuado manejo de los desechos originados por las actividades humanas.

Por ende, la conveniencia de conocer los formatos bajo los cuales la sociedad ha desarrollado patrones de consumo cotidiano de bienes no necesarios, desechables o con embalajes que se consumen de forma rápida y pierden su utilidad al momento [plásticos, materiales de unicel, etiquetas, cartones, etc., que en el fondo contribu- 
yen a satisfacer más bien deseos, antes que necesidades básicas] nos sugirió hacer un recorrido rápido por el concepto rector de este trabajo denominado generación de residuos sólidos domiciliarios (RSD) con el fin de analizar las prácticas de consumo-desecho experimentadas por personas residentes en Juárez, Chihuahua, intentando develar algunas prácticas cotidianas heredadas del pasado.

Ante tal interés, este artículo presenta seis apartados que exponen: I) el planteamiento del problema, 2) el estado de la cuestión, 3) marco contextual del caso de estudio: Ciudad Juárez, 4) el marco metodológico, 5) generalidades del trabajo de campo destacando resultados y hallazgos, y 6) la enunciación de consideraciones finales y recomendaciones.

\section{Planteamiento del problema}

El crecimiento de población ocurrido a nivel mundial de 1950 a 2015 no tiene precedentes. Naciones Unidas estimó que en 1950 el número de habitantes en el mundo alcanzaba los 2600 millones de personas. En 1987, dicha cifra se estimaba en 5000 millones; y en 1999 se alcanzaron 6000 millones. En un lapso de I2 años se experimentó un aumento de I 000 millones de individuos, por lo que en 201 la población del planeta llegó a 7000 millones; pero a mediados de 2015 se estimó haber llegado a 7300 millones de personas (Naciones Unidas, 2017).

De acuerdo con la misma fuente, $60 \%$ de la población vive en Asia; $16 \%$ en África; Io \% Europa; $9 \%$ en América Latina y El Caribe, y el $5 \%$ restante reside en América del Norte y Oceanía. Sin embargo, China e India son los países más poblados al contar con I 400 millones y I 300 millones de habitantes, respectivamente, concentrando más de la tercera parte ( $37 \%)$ de la población mundial. Lo más grave de la situación es que para 2100 Naciones Unidas estima que la población del mundo será equivalente a cerca de ir 200 millones de personas conforme a la proyección de la fecundidad y la mejora en las posibilidades de supervivencia en todos los países.

Este crecimiento requiere estudiarse no solo por la relación directa entre el aumento de la población, el nivel de ingresos y la cantidad de residuos generados a nivel mundial sino por la gravedad que estriba en el incremento per cápita de residuos sin control que, al no tomarse medidas a tiempo, representará un asunto de mayores dimensiones. De ahí la importancia de conocer el estatus global del manejo de los residuos.

El informe emitido por el Programa Ambiental de Naciones Unidas sobre el manejo de la basura a nivel global (UNEP, 2015) expone que la población continúa 
creciendo en los países en desarrollo; la migración ocurre de las áreas rurales a las urbanas y los residuos sólidos per cápita están creciendo al ritmo de los países desarrollados. Y las cifras son alarmantes toda vez que los países más pobres producen cerca de io billones de toneladas anuales de residuos urbanos cuya procedencia se genera en los domicilios, los comercios, la industria y la construcción.

En el caso de los países de la Organización para la Cooperación y el Desarrollo Económico se tiene que la generación de basura o residuos sólidos promedio estimada por habitante (kilogramos per cápita) en 201 fue de 360 en México, 730 en Estados Unidos y 530 en promedio en la OCDE, según el reporte económico, medioambiental y de estadísticas sociales 2014 (OECD, 20I4). En términos generales, la cantidad total de toneladas de basura generadas en cada caso fueron 41063000 en México, 226669000 en Estados Unidos y 66I 458000 como promedio en la OCDE.

Por su parte, la Secretaría del Medio Ambiente y Recursos Naturales (Semarnat) del gobierno de México estimó que la generación de residuos sólidos urbanos en el territorio nacional creció $43.8 \%$ en un lapso de I5 años (1997-20I2) al pasar de cerca de 29.3 a 42.I millones de toneladas como producto del crecimiento urbano, el desarrollo industrial, el cambio en los patrones de consumo, principalmente (Semarnat, 20I2).

En términos per cápita, la Semarnat (2012) informó que los residuos sólidos urbanos (RSU) generados en México se triplicaron al pasar de 300 a 990 gramos per cápita en promedio en el periodo I950 a 201I. Anualmente, dicho cambio pasó de 306 a 360 kilogramos entre 1997 y 2011 , lo que representa un aumento promedio de 3.9 kilogramos por año según la misma fuente. Pero, a reserva de tratar la generación de residuos en un espacio fronterizo, cabe anticipar que la generación de RSU en el país difiere según la región.

Según la Semarnat (20I2a), la región centro representó $5 \mathrm{I}$ \% de la generación total de RSU del país en 20 II y la frontera norte ocupó el segundo puesto al producir I6\% de los Rsu. En tercer lugar se posicionó el entonces denominado Distrito Federal, al representar $12 \%$ del total. El último puesto lo ocupó la región sur. Sin embargo, el dato destacable es que la región norte fue la única que redujo de 1997 a 2011 la generación de RSU al pasar de 6 a 4.4 millones de toneladas.

De no tomarse con seriedad la generación de Rsu en la sociedad contemporánea, y de ocurrir su manejo y disposición inadecuados cabe esperar diversos efectos económicos, medioambientales y en la salud cuyo impacto mayor se reflejará en la calidad de vida de la población en términos negativos.

En palabras de Brown (2003), este impacto requiere atender la cuestión económica en términos de costos-beneficio garantizando financiamientos millonarios que 
permitan hacer frente al incremento de basura a nivel global como a los factores de riesgo que se multiplican por la contaminación del ambiente, a través de enfermedades relacionadas con las vías respiratorias, incluidos los diferentes tipos de cáncer.

Es por ello que la problemática de los residuos responde a dos vertientes, una de carácter estrictamente ambiental y otra de tipo social, político y económico (Esteban, I99Iः 8) y a dos regímenes: el "viejo" y el"nuevo" (Hafkmap, 2002), asociados con los principios y las prácticas aplicadas para la gestión de residuos.

En el caso de ambas vertientes, los gobiernos de cualquier orden (municipal, estatal y federal) deben dar solución a los problemas relacionados con los residuos según establece la Constitución en su artículo II5, fracción III, que ordena: Los municipios tendrán a su cargo las funciones y servicios públicos [... incluidos] limpia, recolección, traslado, tratamiento y disposición final de residuos.

Durante el periodo conocido como "viejo régimen", que abarcó desde mediados del siglo xix hasta principios de la década de 1970, la salud pública y el control sanitario ambiental se priorizaban con base en el principio de que la generación o eliminación de residuos no constituía materia de derecho y que era imprescindible legislar al respecto.

El "nuevo régimen" emergió en 1970 y supuso un cambio en el sentido de dar pautas orientadoras y fundamentos para influir en el diseño de una política en atención al tema de los residuos y orientar a cada gobierno en la gestión de los desechos en cada uno de sus respectivos países.

De esta forma, el cambio de lógica del régimen viejo al nuevo aportó nuevos argumentos, y en el caso mexicano significó poner atención en el aprovechamiento de los recursos involucrados. Una prueba de esto es la reducción de I.6 millones de toneladas de RSU conseguida en la frontera norte entre 1997 y 201 s según se apuntaba líneas arriba.

No puede negarse, como vimos, que el crecimiento de la población a nivel mundial ha modificado los patrones de consumo y de generación de residuos sólidos urbanos y que, en consecuencia, resulta imprescindible abordar, en términos legislativos, lo concerniente a su tratamiento y abordaje. A ello se suma que los RSu generados per cápita en México tienden a la alza. Sin embargo, también es importante destacar el dato de que en la frontera norte del país dicha cifra tiende a reducirse, por lo que se impone el planteamiento central de explorar y dar a conocer cómo ha ocurrido ese proceso en cuanto a la generación y separación de residuos sólidos domiciliarios en Ciudad Juárez, Chihuahua.

El fundamento de atender el problema medioambiental que nos ocupa es la advertencia que señala: el manejo de los residuos sólidos domiciliarios en Juárez 
se caracteriza por carecer de un tratamiento y un control adecuados, pese a que el servicio de recolección lo realiza una empresa reconocida como una gestora exitosa del servicio (Cuoto, Hernández y Sarabia, 2012).

De esta forma, si bien el servicio de recolección es inadecuado y los ciudadanos asumen parcialmente "buenas" prácticas para deshacerse de los residuos en sus domicilios (o basura), previo consumo, será posible distinguir perfiles de grupos de habitantes o de zonas con miras a sugerir, con base en las opiniones de las personas participantes, algunas estrategias diferenciadas que den soporte a la promoción y creación de un sistema de incentivos o sanciones focalizadas (hacia hogares, empresas o la concesionaria) que hagan factible el proceso de separación y reciclaje de RSU así como la reducción de su volumen a nivel local.

En resumen, el objetivo general de este artículo es explorar y conocer las prácticas de consumo-desecho (generación, separación, reciclaje) que se desarrollaban en los domicilios de Ciudad Juárez durante el primer semestre de 2014 para conocer el promedio anual de toneladas diarias recolectadas en la ciudad y distinguir algunas medidas que convendría orientar para focalizar estrategias a favor de la separación y reducción de residuos desde los hogares.

En este afán, se muestra a continuación un esbozo del estado de la cuestión focalizando la discusión del tema de los residuos sólidos a nivel nacional más que en el plano internacional para posteriormente exponer el marco contextual del territorio de interés denominado Ciudad Juárez.

\section{Estado de la cuestión sobre los residuos sólidos en México}

El término residuo, con base en el contenido del sitio Eroski Consumer, puede entenderse como todo aquel material que producimos en nuestras actividades diarias y del que tenemos que desprendernos o deshacernos porque ha perdido su valor o porque ha dejado de ser útil para alguna persona. Los residuos pueden considerarse sinónimos de desechos o del vocablo basura.

Los residuos pueden clasificarse como domésticos, comerciales, industriales, peligrosos, inertes, no peligrosos, biodegradables, radiactivos, sanitarios, residuo de construcción o demolición, entre otros. Sin embargo, para evitar una revisión exhaustiva y su explicación correspondiente en este documento concentramos la atención en los residuos sólidos.

En breve, un residuo sólido se reconoce como un desecho, un sobrante, un producto derivado de una actividad social, productiva, comercial, de servicios, pública 
o familiar (cuadro i). En el pasado, vale insistir, el término «residuos sólidos» se definía como sinónimo de basura y la conceptualización de la problemática giraba en torno a las ideas de "suciedad","desaseo" y la podredumbre asociada con la impresión visual y olfativa de la presencia de la basura (Salgado, 2012). Ahora, la basura representa un recurso en sí o una fuente de otros recursos. En cambio, residuo se asocia con desecho y en su estudio impera el cuidado que exige su relación con la sociedad y el medio ambiente.

\section{Cuadro i. Diferentes aproximaciones de residuo/desecho}

\begin{tabular}{|c|c|}
\hline Fuente & Definición \\
\hline Programa 2I, 1992* & $\begin{array}{l}\text { Los desechos sólidos [...] comprenden todos los residuos } \\
\text { domésticos y los desechos no peligrosos como los comercia- } \\
\text { les e institucionales, las basuras de la calle y los escombros } \\
\text { de la construcción. }\end{array}$ \\
\hline $\begin{array}{l}\text { (вBV, 1993) } \\
\text { Banco Bilbao- Vizcaya. Dic- } \\
\text { cionario de la naturaleza }\end{array}$ & $\begin{array}{l}\text { Residuo: cualquier forma material o forma de energía des- } \\
\text { cargada al medio ambiente por el hombre y susceptible de } \\
\text { producir contaminación. }\end{array}$ \\
\hline $\begin{array}{l}\text { (Seóanez, 2000) } \\
\text { Dentro del Capítulo III } \\
\text { de la Ley Io/1998**. Cap. } 20\end{array}$ & $\begin{array}{l}\text { Residuo: cualquier sustancia u objeto perteneciente a alguna } \\
\text { de las categorías que figuran en el manejo de la Ley de Resi- } \\
\text { duos, del cual su poseedor se desprenda o del que tenga la } \\
\text { intención de desprenderse. }\end{array}$ \\
\hline $\begin{array}{l}\text { (Seóanez, 2000) } \\
\text { Dentro del Capítulo III de } \\
\text { la Ley Io/1998. Capítulo } 20\end{array}$ & $\begin{array}{l}\text { Residuos urbanos o municipales: los generados en los domi- } \\
\text { cilios particulares, en los comercios, oficinas y servicios, así } \\
\text { como todos aquellos que no tengan calificación de peligro- } \\
\text { sos y que por naturaleza o composición puedan asimilarse } \\
\text { a los producidos en los anteriores lugares o actividades. }\end{array}$ \\
\hline $\begin{array}{l}\text { (LGEEPA,2OI4) } \\
\text { XXXII/art } 3^{\circ}\end{array}$ & $\begin{array}{l}\text { Residuo: cualquier material generado en los procesos de } \\
\text { extracción, beneficio, transformación, producción, consumo, } \\
\text { utilización, control o tratamiento cuya calidad no permita } \\
\text { usarlo nuevamente en el proceso que lo generó. }\end{array}$ \\
\hline $\begin{array}{l}\text { (PNUMA Y SEMARNAT, } \\
\text { 2004) }\end{array}$ & $\begin{array}{l}\text { Residuo: material o producto cuyo propietario o poseedor } \\
\text { desecha y que se encuentra en estado sólido o semisólido, o es } \\
\text { un líquido o gas contenido en recipientes o depósitos, y que } \\
\text { puede ser susceptible de ser valorizado o requiere sujetarse } \\
\text { a tratamiento o disposición final conforme a lo dispuesto en } \\
\text { esta Ley y demás ordenamientos que de ella deriven. }\end{array}$ \\
\hline
\end{tabular}




\begin{tabular}{|l|l|}
\hline Fuente & Definición \\
\hline (PNUMA Y SEMARNAT, & $\begin{array}{l}\text { Residuos sólidos urbanos: los generados en las casas habi- } \\
\text { tación, que resultan de la eliminación de los materiales que } \\
\text { utilizan en sus actividades domésticas de los productos } \\
\text { que consumen y de sus envases, embalajes o empaques; } \\
\text { los residuos provienen de cualquier actividad dentro de un } \\
\text { establecimiento o en la vía pública que genere residuos con } \\
\text { características domiciliarias, y los resultantes de la limpieza } \\
\text { de las vías y lugares públicos. }\end{array}$ \\
\hline
\end{tabular}

Notas *Véase <http://www.un.org/spanish/esa/sustdev/agenda2I/agenda2Ispchapter2I.htm $>{ }^{* *}$ Se crea dentro del marco jurídico en la Unión Europea. En este apartado se elimina, del término Residuos Sólidos Urbanos, la parte de "sólidos" y solamente se denominan Residuos Urbanos. Para ampliar la información véase: <https://www.boe.es/buscar/doc.php?id=BOE-A-1998-9478>

Fuente: Elaboración propia con base en autores y documentos referidos.

La revisión de literatura sobre el estudio de la basura nos sugirió que la publicación pionera interesada en el problema de los residuos sólidos a nivel mundial considerando el incremento del consumo de bienes y recursos en la sociedad estadounidense influenciada por la mercadotecnia, la publicidad y la imposición de estándares falsos fue The Waste Makers, de Vance Packard (1960).

En palabras de Bernache et al. (1998), dicha publicación buscó sondear la creciente comercialización de la vida en ese país donde fabricantes y anunciantes buscaban persuadir a los consumidores para que compraran mercancías que no necesitaban apelando al concepto de obsolescencia planificada y estableciendo una fecha de caducidad en los productos para que se desgastaran más rápidamente y requirieran ser reemplazados en menor tiempo.

En nuestro entender, esa persuasión estimuló el consumo de la sociedad a tal grado que provocó no solo un ritmo de producción creciente de bienes sino incrementó la generación de toneladas de basura y desperdicio a un ritmo exponencial.

Entre la bibliografía que a nivel internacional se ha posicionado como referencia en el siglo XXI, según el informe de la OECD (20I4), para estudiar las iniciativas, los sistemas de manejo de residuos o de la basura, los indicadores propuestos para monitorear el estatus de los países, los programas de prevención, entre otros destacan: Armijo et al. (2OII), Bringhenti et al. (20IO), Серт University (20IO), Greene y Tonje (2014), Hotta et al. (2014), Menes et al. (20II), Ministry of Urban Development of 
India (2010), Polaz y Teixeira (2009), Romualdo (2014), Wilts (2012) y Zaman y Lehmann (2013).

En general, los estudios más recientes han intentado proponer metodologías de análisis, evaluar programas, hacer análisis del agua, la sanidad y de los residuos sólidos, monitorear el progreso de los territorios en los esfuerzos de las 3R (reducir, reusar y reciclar) para conseguir economías verdes, revisar los procesos de reciclaje, tratamiento y disposición de los residuos, proponer sistemas de evaluación e indicadores de sustentabilidad, desarrollar índices de basura cero o residuos cero para medir la efectividad en el manejo de los residuos sólidos, entre otros aspectos.

De manera particular, los estudios se han aplicado en ciudades individuales de países como Brasil, India, Estados Unidos, Portugal, Tailandia, España, Alemania; o por regiones, distinguiendo los países de bajo, medio o alto ingreso.

La tendencia apunta a que los temas principales de estudio relacionados con los residuos serán: definir los conceptos, probar los indicadores, informar del estatus del manejo de los residuos a nivel global, establecer cuál será el rumbo de la gobernanza de los residuos, legislar en materia de salud pública, medioambiental y en razón de la recuperación de los recursos, fijar los modelos de financiamiento y emitir recomendaciones para identificar las prioridades de la agenda global en el futuro.

¿Y qué ocurre en el caso de México? La revisión bibliográfica apunta a que la aportación teórica más importante ocurrió en la década de los ochenta del siglo xx. Tal publicación se orientó para comprender la dinámica de los residuos sólidos urbanos donde el foco principal de atención fue la Ciudad de México.

Los temas de discusión vigentes en ese entonces se centraban en los estudios de caracterización de los residuos [composición orgánica, inorgánica, peligrosa, etc.] y las condiciones que presentaba el sector informal de trabajadores o pepenadores que separaban los residuos aprovechables bajo condiciones de riesgo en los sitios de disposición final (Bernache, 2007).

Para la década de los noventa del mismo siglo, la agenda de investigación en torno al manejo de los residuos sólidos urbanos (RSU) no solo aumentó sino que vino a consolidar nuevas líneas de estudio en otras ciudades del país. Dichos análisis tuvieron mayor atención en ciudades como Mexicali, Guadalajara y Morelia, y sus principales estudiosos fueron Buenrostro (200I) y Bernache (2007), entre otros.

Pero, pese a los avances conseguidos sobre los temas de producción de residuos, salud y contaminación causada por la basura, aquellos arrojaron un vacío de investigación que se centró en la conveniencia de estudiar las problemáticas que rebasaban la acción de los gobiernos municipales ante el intenso proceso de urbanización. 
Tan fuerte fue tal proceso que para finales del siglo $\mathrm{xx}$ se contaban más de 100 ciudades en el país que registraban más de 100000 habitantes cada una (Ariza, 2003), por lo que se requerían trabajos que dieran cuenta de la complejidad creciente de los procesos que involucraba la basura.

Por ello, ante el cometido de reforzar las políticas ambientales en México, en I999 se presentó un proyecto sobre el manejo integral de los residuos sólidos con un nuevo enfoque donde se atendiera la "Jerarquía del manejo de residuos sólidos".

En suma, los responsables de ese proyecto tuvieron la responsabilidad de priorizar las opciones de manejo de los residuos en un orden de preferencia que partiera de la prevención de la generación, el re-uso, el reciclaje, el compostaje y la incineración con recuperación de energía, hasta el confinamiento de los residuos en rellenos sanitarios como la última opción (INE, I999).

A partir de esta jerarquización se desprendió la propuesta relacionada con el manejo de los residuos sólidos domiciliarios (RSD) que consistía en poner en marcha las denominadas $3 \mathrm{R}$, tal como ocurría en el plano internacional, para conseguir la reducción en las cantidades producidas.

Sin embargo, a partir del año 2000 la preocupación por tratar los problemas ambientales ocasionados por el incremento de los residuos en las investigaciones siguió avanzando, por lo que de forma más específica y concreta se expidió la Ley General para la Prevención y Gestión Integral de Residuos (LGPGIR, 20I4) vigente en el país desde 2004.

En resumen, los tres ejes importantes susceptibles de análisis consistieron en conseguir: i) la efectividad ambiental, ii) la viabilidad económica y, iii) la aceptación social del sistema de gestión de residuos. Por ende, el territorio nacional entró en una dinámica en favor de adoptar medidas enfocadas a una disminución en las toneladas recolectadas de residuos sólidos para hacer frente a los incrementos de los costos inherentes en la operación de los servicios de barrido, recolección, traslado y depósito de desechos, tratamiento y compactación, etcétera.

De esta forma, la necesidad de realizar estudios comparativos sobre los RSU en México implicó que autores como Ramírez y Chávez (1998) asumieran este encargo y compararan el desempeño del servicio de limpia en la década de 1990 considerando cuatro municipios del área metropolitana de Guadalajara en su propuesta.

No sorprende que concluyeran que los ayuntamientos cumplían y se limitaban a brindar el servicio público de recolección de basura bajo el costo de que la inversión presupuestal en cada caso era muy elevada. Las debilidades encontradas confirmaron que las labores de información proporcionada a la población respecto de la manera en que se otorgaba el servicio eran escasas y que la supervisión que se daba a las 
acciones de los empleados en el servicio de limpia y la que se dirigía a la empresa responsable concesionaria era insuficiente.

Buenrostro (200I) realizó otro estudio, pero centrado en Morelia. Entre sus hallazgos destacó que las autoridades no contaban con información ni registros mínimos sobre la infraestructura y la operación del servicio de recolección, siendo este un grave problema por la ineficacia para mantener un control de las operaciones, un registro de la generación, la recolección per cápita y las toneladas que se confinaban.

El servicio de limpia municipal, prestador del servicio en esa ciudad, solo contaba con una gestión de residuos mínima y se basaba en un viejo régimen de recolección por cuya causa, mientras la ciudad crecía vertiginosamente, prevalecía en ella una nula administración ambiental de su basura.

En suma, coincidiendo con Bernache (2007), pese a los esfuerzos e iniciativas implementadas, no se logró consolidar estrategias eficientes del modelo de sustentabilidad de los residuos sólidos urbanos a gran escala en el país; por lo que Rodríguez (2008) no descartó la posibilidad de desarrollar este tipo de estrategias haciendo alusión a ciudades mexicanas cuyo desempeño en el manejo de residuos se considerara exitoso.

Entre dicha ciudades se incluían Monterrey, Nuevo Laredo, Tlalnepantla, Tecámac, Coatzacoalcos, Ciudad Juárez, Aguascalientes, Mérida, Puebla, Querétaro, Culiacán, Durango, Irapuato y León, principalmente; donde la particularidad común fue que estos municipios establecieron alianzas con el sector privado o hicieron uso de recursos económicos aportados por programas a nivel federal (Tejeda, 2013). Y al parecer, este modelo ha funcionado.

En conclusión, los retos advertidos por las investigaciones realizadas, tal como observaron Deffis (1994), Ojeda et al. (2000), Hülstrunk (2008) o Trejo (1994), en sintonía con lo acontecido en el plano internacional, consistieron no solo en enfatizar el potencial de reciclaje que poseen los residuos domiciliarios sino en la importancia que reviste monitorear el impacto de la reducción de la cantidad de residuos destinados para su disposición final.

Por ello, medidas como documentar el aprovechamiento de los residuos para reducir las cargas medioambientales, señalar la recuperación de residuos reciclables secos como papel, cartón, metales y vidrio —más allá de considerarles como desperdicios marginales-, reconocer la riqueza de realizar estudios de caracterización de RSU para revelar que los residuos reciclables constituyen $80 \%$ del total de los residuos (Restrepo y Phillips, 1985; Bernache, 2007; Buenrostro y Bocco, 2003; Ojeda, Armijo y Ramírez, 2000) se admiten como prioritarias en la agenda. 
Ante esta conveniencia, y dado que Ciudad Juárez se advierte como una experiencia exitosa según el listado de Rodríguez (2008), observemos a continuación cuál es el contexto y las circunstancias que prevalecen en esa urbe respecto del manejo de los residuos sólidos de forma que se cumpla el propósito de conocer las generalidades de la empresa concesionaria y verificar el comportamiento en el promedio de toneladas diarias recolectadas de Rs anualmente.

\section{Contextualización de Juárez y datos generales del manejo de los residuos sólidos}

Juárez es un municipio ubicado en el estado de Chihuahua cuya población total ascendía en 2010 a I.3 millones de habitantes, según el Censo Poblacional (INEGI, 20I0). La localidad se sitúa a orillas del Río Bravo y geográficamente se ubica en la mesa central de la región norte de México (figura I). La densidad de población ( 3744.24 habitantes $\left./ \mathrm{km}^{2}\right)$ sugiere que es la urbe más dispersa entre las ciudades de más de un millón de habitantes, según el Instituto Mexicano de Competitividad (IMCO, 20I4).

En cuanto al crecimiento sociodemográfico de la ciudad, Rubio indica que durante el periodo transcurrido entre 1940 y 2000 la cantidad de habitantes pasó de poco más de 55000 personas a más de I.2 millones, lo cual significa que en un lapso de seis décadas la población se multiplicó poco más de 20 veces (Rubio, 2005: 38).

Figura i. Localización de Ciudad Juárez, Chinuahua. México

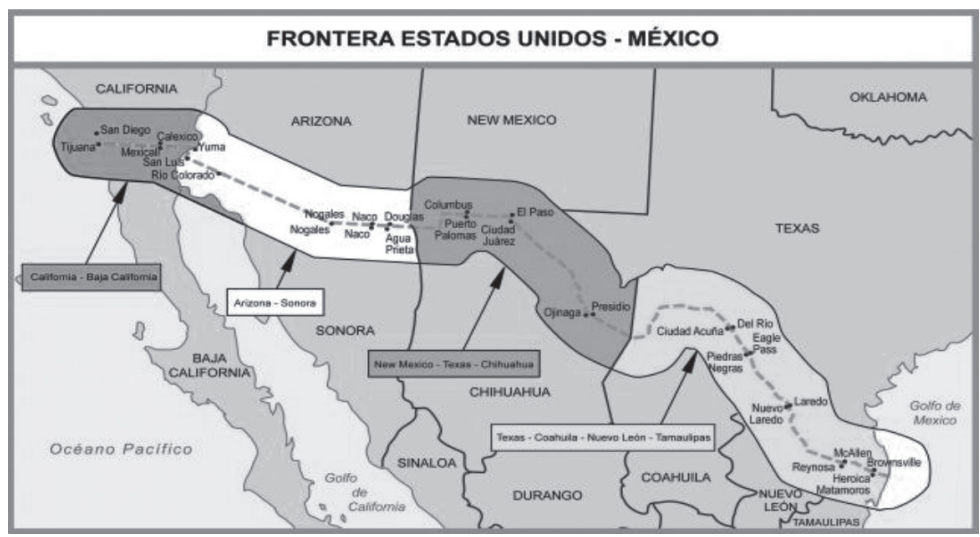

Fuente: Tomado del Programa ambiental México Estados Unidos: Frontera 2012. 
Dicho crecimiento, según el autor, se soportó en la instalación de la industria maquiladora en la década 1970, sumado al auge agrícola de los valles productivos de la región, así como por la alta migración convocada por el incremento de nuevos establecimientos y empleos que demandaban trabajadores. El resultado fue un crecimiento desmedido de la mancha urbana que aumentó la demanda de servicios urbanos y la dotación de servicios en general.

Tal incremento poblacional y demandas aledañas propiciaron la multiplicación en la generación de residuos, la exigencia de un proceso de recolección, transporte y disposición final eficientes. Si centramos la atención en la generación de residuos, cabe anticipar que las cifras documentadas en diversas fuentes son contradictorias.

Por ejemplo, Cuoto et al. (2012) registra que en 2010 se generaban en Ciudad Juárez I 250 toneladas diarias de basura provenientes de casas habitación y dependencias de gobierno. Héctor Lozoya, titular de la Dirección de Limpia en la década 20I0, declaró que a principios de 2014 se levantaban al día en esa ciudad entre 800 y I 200 toneladas de desechos domiciliarios en un rango de I 200 colonias; y desde el segundo semestre de 2014 dicha cifra aumentó de I 200 a I 500 toneladas.

Las razones del incremento en la generación de basura se debieron, en palabras del funcionario, al aumento de personas que volvieron a la ciudad y a la apertura de más comercios. De este modo, el número mayor de toneladas implicó el alza en el costo del servicio (El Diario, 24 de abril de 2014).

En cuanto al servicio, la empresa concesionaria es Promotora Ambiental de la Laguna (PASA) e inició su contrato con el municipio en 2006. Entre los servicios concesionados se cuentan: aseo urbano (léase barrido manual y mecánico), recolección, traslado y depósito de los desechos sólidos de carácter domiciliario y de edificios públicos municipales, tratamiento y compactación de los residuos, entre otros.

Según Cuoto (2008), Cuoto et al. (2012 ) y El Diario (24 de abril de 2014), esta concesionaria se concentra en la recolección de desechos en casas habitación $(385000-400000 \mathrm{~kg})$ y a comercios generadores de menos de io kgs/día. La frecuencia de recolección es de tres veces por semana: lunes, miércoles y viernes opera en la zona norte y martes, jueves y sábado en la zona sur. En el caso de la zona centro, el servicio funciona seis días a la semana.

PASA, al solicitar la renovación de la concesión, en abril de 20I4, expuso al municipio que el comportamiento de la recolección de residuos tendió a la baja en los ocho primeros años de su operación (gráfica I), consiguiendo que de I 148 toneladas diarias recogidas en 2006 pasó a $948000 \mathrm{~kg}$ en 2014; pese a que la meta estimada eran I 200 toneladas diarias. 
Gráfica i. Promedio de toneladas diarias recolectadas de residuos SÓLIDOS EN JUÁREZ, 2006-20I4

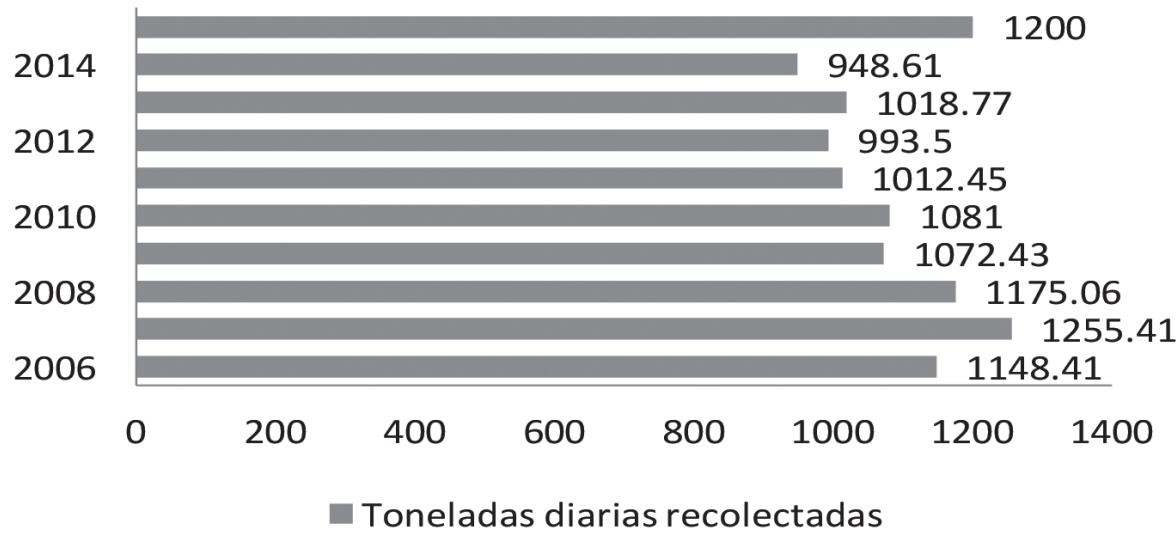

Fuente: Heroica Ciudad Juárez. Secretaría de Ayuntamiento. Abril 2014. Oficio número Reg/ ARR/580. <http $: / / w w w . j u a r e z . g o b . m x / 2015 c f /$ transparencia/docs.php?file $=13612830>$.

En síntesis, puede aseverarse que la recolección de residuos sólidos en Ciudad Juárez sí ha ido descendiendo desde el año 2000, pero se requiere fomentar la participación ciudadana en esta corresponsabilidad de forma que la reducción del daño ecológico permita prolongar la vida útil de los residuos y logren delinearse estrategias para su minimización.

De ahí la conveniencia de hacer extensiva la preocupación de esta situación y buscar definir las acciones que habrán de coadyuvar para disminuir el impacto ambiental que genera el uso y tratamiento inadecuado de los residuos; de ahí surgió la idea de realizar una tesis de posgrado que, con base en el diseño y la aplicación de cuestionarios, admitiera sistematizar las experiencias y prácticas de las personas en razón de ser generadoras de basura o de productoras de residuos en los domicilios.

Ante esta oportunidad, se optó por efectuar el trabajo de campo con la participación de padres y madres de familia cuyos hijos e hijas estudiaran algún grado de educación primaria o secundaria en algún plantel de la localidad. Pero para mostrar más detalles de esta tarea se exponen a continuación los parámetros generales del diseño metodológico, así como una selección de los resultados obtenidos. 


\section{El método, la muestra y el levantamiento de información}

El diseño de la investigación enmarcado desde la lente cuantitativa llevó a resolver que la alternativa adecuada para levantar información sobre las experiencias y prácticas de las personas respecto de la tarea cotidiana de generar desechos o residuos en los domicilios era aplicar cuestionarios.

La principal justificación fue que el cuestionario, más allá de formular preguntas, codificar respuestas y hacer un informe del análisis, representa una estrategia de investigación social cuyo formato se ciñe a la formulación del problema que requiere un diseño muestral a partir del concepto de población.

Sobre el concepto, Sabino (1992) indica que la población —o conjunto universo- no es más que la totalidad del fenómeno a estudiar donde los individuos participantes poseen una característica común, lo cual se estudia y da origen a los datos de la investigación, y Ramírez (1999) propone que la población es un subconjunto del universo conformado en atención a un determinado número de variables que se van a estudiar.

En concreto, ambos autores coinciden en el hecho de que la población es un conjunto de individuos que presentan características en común y que serán sometidos a algún tipo de estudio cuya validez, agregaríamos, requiere no solo redactar un instrumento como el cuestionario sino que demanda revisarlo, probarlo y editarlo para aplicar la versión final a una muestra previamente seleccionada.

$\mathrm{Al}$ respecto, Sabino (1992) indica que la muestra implica considerar una parte de la población que es un número de individuos o de objetos seleccionados, cada uno de los cuales debe ser representativo del universo de procedencia que ha de contener todos los elementos en la misma proporción del aspecto que se desea estudiar. Pero Martínez (199I) define la muestra como "un grupo relativamente pequeño de una población que representa características semejantes a la misma”.

$\mathrm{Al}$ contrastar las opiniones de estos dos autores se hace notoria la importancia de que la muestra, para ser calificada como tal, debe provenir de la población en estudio. Por ello, esta pauta estimó pertinente resolver que los datos que proporcionaría el trabajo de campo debería hacer posible describir mediante un análisis empírico la importancia que revisten las acciones que motivaban o podían motivar cambios en las prácticas de consumo-desecho (generación, separación y reciclaje) de los habitantes que vivían en Ciudad Juárez en 2014.

Por consecuencia, se resolvió que el diseño de la investigación cuantitativa vía aplicación de cuestionarios sería de tipo exploratorio y que la muestra de personas interrogadas permitiría registrar sus respuestas de manera individual en un ins- 
trumento o cédulas de registro, cuya aplicación fuera cara a cara y cuyo contenido final proviniera de la fase de prueba piloto. Esta sistematización consideraría las reflexiones y sesiones atendidas en el curso de Seminario de Tesis I de los estudios del posgrado.

El diseño de la muestra, al igual que el proceso de levantamiento de la información, el encuentro cara a cara con las personas encuestadas, el proceso de captura, el periodo de validación, la fase de análisis de los datos, y toda la serie de acciones realizadas en esta tarea fueron regidos por un calendario previamente establecido cuyo ejercicio comprendió de enero a diciembre 20I4, y la fase de escritura, análisis de datos, asesorías para la interpretación de resultados, revisión de fondo del contenido, etc., sucederían en el transcurso del siguiente año, 2015. En síntesis, los resultados de estas tareas arrojaron lo siguiente.

\section{Trabajo de campo y resultados obtenidos}

La fase piloto del trabajo de campo se realizó en enero-mayo de 2014 en diversos centros comerciales de la localidad lo que permitió examinar nuevamente y revisar el cuestionario como una edición final de ese instrumento, además de tener una primera aproximación de las circunstancias del tema en consideración.

Una siguiente etapa pretendía hacer un siguiente levantamiento de información en un número mayor de centros comerciales atendiendo las lecciones aprendidas, pero las circunstancias lo impidieron por lo que se requirió resolver y tomar decisiones sobre un tema central: dónde acudir y con quién para aplicar los cuestionarios definitivos. Y adicionalmente hubo que resolver y realizar la selección y formación del grupo de entrevistadores(as).

Luego de atender un amplio número de ajustes y recomendaciones, se resolvió que el cuestionario debía dirigirse a padres y madres de familia que vivieran en Juárez en el periodo del levantamiento. La estrategia idónea para tener ese contacto fue relacionarse con agentes clave del sector educativo consiguiendo la participación de padres y madres de seis centros de educación básica (tres escuelas primarias y tres planteles de nivel secundaria) localizados en el poniente o el oriente de la urbe (figura 2), de modo que la muestra resultara más representativa en la presentación de los resultados.

Las escuelas seleccionadas en la muestra fueron: I) Colegio Isaac Newton; 2) Escuela Primaria Ramón López Velarde; 3) Escuela Primaria Miguel Ahumada núm. 2289; 4) Escuela Secundaria Técnica núm. 84; 5) Escuela Secundaria Estatal 
núm. 30I6; y 6) Escuela Federal I6-ES-98 (figura 2). Según puede observarse, las primeras tres de la lista se ubican en el poniente de la ciudad y las identificadas como 4,5 y 6 se localizan en el oriente de la localidad.

\section{Figura 2. Distribución de escuelas primarias y SeCUndarias colabo-} RADORAS EN EL TRABAJO DE CAMPO

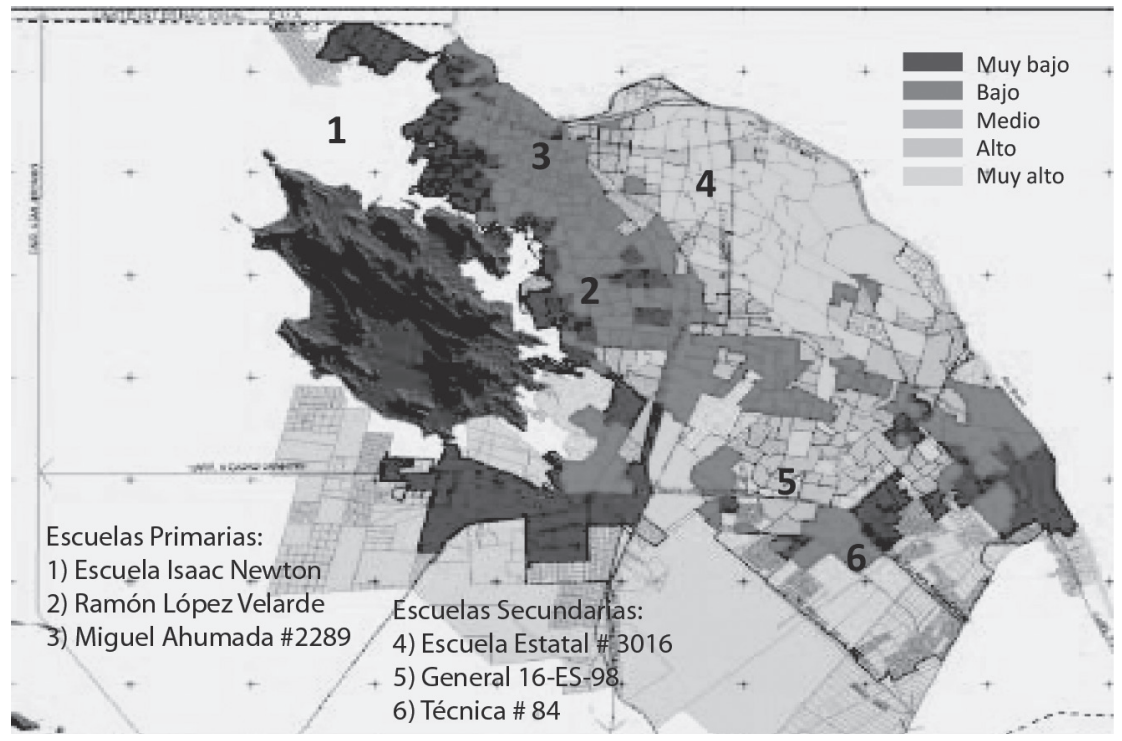

Fuente: Adaptado de PDU (20I0) con datos del IMIP (2005)

El proceso de recolección de datos exigió llevar a cabo un ejercicio de cálculo de la muestra mínima requerida en términos de individuos cuya característica en común fuera que cumplieran la condición de ser padre o madre de familia (con 20 años o más de edad) y que por lo menos demostraran tener uno o una estudiante inscrita en la escuela seleccionada.

De acuerdo con la metodología de la Universidad de Granada, el cálculo del tamaño óptimo de la muestra, considerando una estimación de proporciones bajo el supuesto de que $p=q=50 \%$ (donde la probabilidad de elegir a una persona $u$ otra es similar) con una población de 750264 con 20 años o más de edad registrada en Juárez con un margen de error máximo admitido de $5 \%$, fue igual a 384 cuestionarios para un nivel de confianza de 95\%, 47I para un nivel de confianza de $97 \%$ y 665 individuos o cédulas para un nivel de confianza de $99 \%$ (cuadro 2). 
Aunque se corrió el riesgo de que estadísticamente no se considerara el trabajo de campo estrictamente significativo por las limitaciones propias que se reconoce al aplicar cuestionarios [como es el hecho de que posibilitan el estudio de hechos y aspectos desde posturas subjetivas o que permite la obtención de un gran volumen de información pero puede resultar difícil diferenciar las relaciones entre las variables de las verdaderas variables causales], vale reconocer que los datos obtenidos en este estudio son representativos en su nivel de explicación al asumir un alcance exploratorio.

Cuadro 2. Consideraciones de la muestra

EN LA FASE DE TRABAJO DE CAMPO

\begin{tabular}{|l|c|}
\hline Municipio & Juárez \\
\hline Localidad & Ciudad Juárez \\
\hline Población del rango de edad (de 20 años y más) & 750264 \\
\hline $\begin{array}{l}\text { Muestra sugerida estadísticamente } \\
\text { Criterio de selección: madres y padres de familia de estudiantes de } \\
\text { primaria y secundaria (20 años o más de edad en el periodo del } \\
\text { levantamiento) (95\% N.C.) }\end{array}$ & 384 \\
\hline $\begin{array}{l}\text { Muestra sugerida estadísticamente } \\
\text { Criterio de selección: madres y padres de familia de estudiantes de } \\
\text { primaria y secundaria (20 años o más de edad en el periodo del } \\
\text { levantamiento) (97\% N.C.) }\end{array}$ & 47I \\
\hline $\begin{array}{l}\text { Muestra sugerida estadísticamente } \\
\text { Criterio de selección: madres y padres de familia de estudiantes de } \\
\text { primaria y secundaria (20 años o más de edad en el periodo del } \\
\text { levantamiento) (99\% N.C.) }\end{array}$ & 665 \\
\hline $\begin{array}{l}\text { Cuestionarios aplicados (fase del levantamiento con fin exploratorio) } \\
\text { Cuestionarios validados (Prueba Cronbach, Chi cuadrada) }\end{array}$ & \begin{tabular}{l} 
6oo \\
\hline $\begin{array}{l}\text { Descripción de la población muestral de los planteles educativos } \\
\text { según el registro de la SEP }\end{array}$
\end{tabular} \\
\hline $\begin{array}{l}\text { Consideraciones: Para la aplicación de la encuesta se emitió una } \\
\text { convocatoria para padres y madres de familia }\end{array}$ & $\begin{array}{l}\text { Datos: Ciclo esco- } \\
\text { lanero-Junio } \\
\text { cionadas }\end{array}$ \\
\hline
\end{tabular}

Fuente: Elaboración propia con base en el levantamiento en las aulas. 
El formato seguido para lograr el encuentro entre entrevistadores o interrogadores y personas entrevistadas consistió en emitir una convocatoria previos acuerdos con las autoridades escolares de cada centro educativo para realizar reuniones masivas en un horario, una fecha y un salón específicos; consiguiendo captar 600 personas en los diversos planteles educativos. De resultar válidos el total de cuestionarios, significaría que el nivel de confianza de los resultados obtenidos rebasaría el $97 \%$.

Dichos cuestionarios se revisaron, se realizaron los análisis de confiabilidad y viabilidad con fines de validar la información recogida susceptible de análisis con la prueba Alfa de Cronbach (cuadro 3), por lo que resultó una validación final de 530 cuestionarios; cifra que rebasa los 47I requeridos para asumir un nivel de confianza de $97 \%$. En resumen, el estadístico de Cronbach, que equivalió a 0.07I puntos significa que los ítems sí atienden una consistencia interna por lo que sí son susceptibles de ser sus datos analizados.

Cuadro 3. Análisis y prueba de Confiabilidad

\begin{tabular}{|l|l|c|c|}
\hline \multicolumn{2}{|c|}{} & $\mathrm{N}$ & $\%$ \\
\hline \multirow{3}{*}{ Casos } & Válidos & 530 & 100.0 \\
\cline { 2 - 4 } & Excluidos(a) & 0 & 0.0 \\
\cline { 2 - 4 } & Total & 530 & 100.0 \\
\hline Alfa de Cronbach & $0.07 \mathrm{I}$ & N de elementos & 3 \\
\hline
\end{tabular}

Fuente: Elaboración propia con los datos obtenidos en el trabajo de campo. Incluye eliminación por lista basada en todas las variables del procedimiento.

En el caso del contenido del instrumento se tiene que la elaboración del cuestionario se diseñó con preguntas - en su mayoría con respuestas cerradas- que ya se habían aplicado y replicado para otras zonas metropolitanas del país con el propósito de conocer los elementos socioculturales y ambientales que impactaban el fracaso o el éxito de la separación de basura o residuos en las fuentes generadoras.

Y en el caso de Ciudad Juárez, un instrumento similar lo utilizó Villalpando (20II) registrando importantes observaciones diagnósticas de las prácticas del manejo de los residuos en los hogares pero con la peculiaridad de atender al análisis con un enfoque de género.

En este caso, la investigación en turno consideró la pertinencia de retomar algunas preguntas de los autores citados pero adecuándolas y editándolas con el objetivo de obtener información que nos llevara a conocer bajo cuáles incentivos, según las 
respuestas de la gente, podría lograrse o sería más probable obtener o estimular a que la gente separe los residuos desde sus domicilios.

En concreto, los resultados obtenidos que se presentan en esta ocasión son producto del análisis y respectivas tareas de codificación, tabulación e informes parciales que se elaboraron previamente con el auxilio de la utilización de los programas SPSS y Excel durante las jornadas de trabajo atendidas en 2015.

\section{Análisis de los resultados}

El contenido del cuestionario aplicado a las personas participantes incluyó disponer de una gama de indicadores susceptibles de interpretar y evaluar que no se limitaran a valorar los perfiles sociodemográficos o características en términos cuantitativos sino que además de conocer la edad, el sexo, el estatus conyugal y otros datos de las personas interrogadas permitieran revisar detenidamente los datos arrojados por más de 50 variables disponibles que proporcionaran información para confirmar o rechazar los objetivos de esta investigación y la hipótesis que guiaron esta investigación.

Un primer aspecto que resultó de la fase inicial del análisis de datos obtenidos llevó a reconocer que los planteles elegidos permitieron observar el amplio radio de influencia que estos ejercen en las zonas de residencia de las familias dada la gran dispersión geográfica, que abarca 155 colonias. Ello dio cuenta de las largas distancias que han de recorrer los estudiantes día con día a costa de hacer frente a mayores gastos y disponibilidad de tiempo para tener acceso a la educación.

Hecha esta anotación, se presentan los resultados sobre el estudio en consideración atendiendo tres apartados: I) el perfil sociodemográfico de las personas interrogadas, 2) las respuestas relacionadas con las características de los residuos generados $y, 3$ ) las prácticas de consumo-desecho (generación, separación y reciclaje) declaradas por nuestros informantes.

\section{Perfil sociodemográfico de los encuestados}

La muestra de datos se dividió en diferentes ítems sociodemográficos para definir el perfil del informante. Las variables consideradas fueron género, edad, estatus conyugal y nivel escolar. 
En el caso del género, la valoración estadística fueron 530 personas, de las cuales 288 eran hombres y 242 mujeres, lo que se aproximó a representar casi $50 \%$ cada grupo según establece la condición $p=q=0.50$.

En el caso de la edad de los y las participantes se obtuvo una distribución casi homogénea ya que $33 \%$ declaró contar con 15 a 29 años cumplidos al momento de contestar el cuestionario, $38 \%$ indicó tener entre 30 y 44 años y el resto $(29 \%)$ expresó tener 45 años o más (cuadro 4).

\section{Cuadro 4. Género y edad de los encuestados}

\begin{tabular}{|l|l|l|l|}
\hline Género & Porcentaje & Edad & Porcentaje \\
\hline Mujeres & $46 \%(242)$ & I5 a 29 años & $33 \%(175)$ \\
\hline Hombres & $54 \%(288)$ & 30 a 44 años & $38 \%(201)$ \\
\hline Total & I00\%(530) & 45 años o más & $29 \%(154)$ \\
\hline & & Total & I00\%(530) \\
\hline
\end{tabular}

Fuente: Elaboración propia con los datos obtenidos en el trabajo de campo.

En el caso de la situación o estatus conyugal reconocido se obtuvo que tres de cada io (34\%) de los interrogados reportó estar soltera/o. Una cuarta parte (27\%) respondió estar casada/o y uno de cada io (15\%) refirió estar divorciada/o. En menor proporción se encontraron aquellos en estatus de unión libre ( $14 \%$ ) o en condición de viudez (4\%). Una novedad es que $6 \%$ de las mujeres reconoció su estatus de madres solteras (gráfica 2).

Para el ítem del nivel de escolaridad sorprendió el predominio de personas con estudios de preparatoria ( $36 \%$ ) o con educación superior trunca (23\%). En la segunda categoría se ubican aquellos padres o madres que declararon haber terminado la secundaria o la universidad. $Y$ en tercer plano se incluyen los grupos extremos que señalaron tener solo educación primaria o estudios de posgrado en la misma proporción (3\%) (gráfica 2).

Según se ha dicho, la muestra poblacional cuestionada se distribuyó a lo largo de I55 colonias de la ciudad, equivaliendo a alrededor de 15.96\% del total de colonias, según el registro de la Dirección de Limpia que contabilizó 940 colonias, en 2014, donde se realizaban la recolección de basura doméstica, barrido y mejoramiento de imagen urbana en la ciudad (www.juarez.gob.mx).

En concreto, $50.9 \%$ de las personas registraron en las cédulas que sus domicilios de residencia se ubicaban en el poniente de la ciudad y 49.1 \% refirió residir en 


\section{Gráfica 2. Estado civil y Nivel de escolaridad de los encuestados}

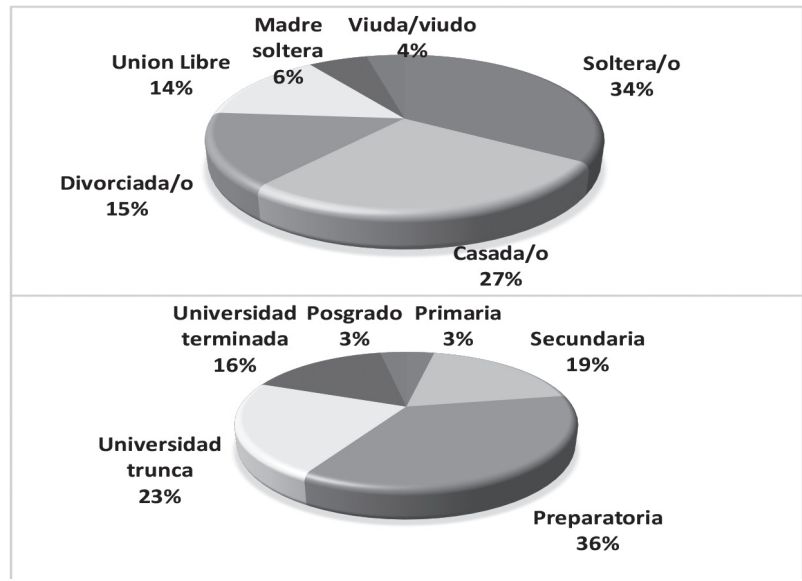

Fuente: Elaboración propia con base en el levantamiento en las aulas.

el oriente, lo que sí cumple con el criterio de haber interrogado a una población homogénea en esta distribución y el criterio de $p=q=0.50$.

Por lo que respecta a las experiencias de separación de residuos en los domicilios se obtuvo lo siguiente: la tendencia por parte de las personas en la acción de separar los residuos domiciliarios fue favorable en el sector oriente al representar la mayoría (52.5\%) y en el sector poniente fue mayor el porcentaje de los que no separan (52.7\%). O sea, mientras que la minoría no separa en el oriente, la minoría separa en el poniente (gráfica 3 ). No obstante, resulta importante reconocer que cuatro o cinco de cada io personas en el oriente o poniente de la ciudad sí separa los residuos en sus domicilios.

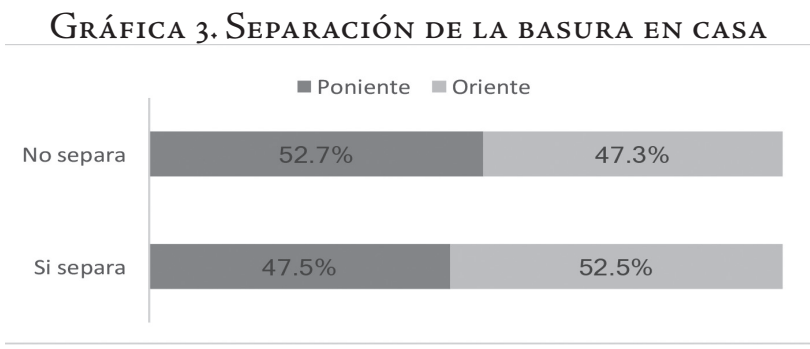

Fuente: Elaboración propia con los datos obtenidos en el trabajo de campo. 
$\mathrm{Al}$ respecto, cabe puntualizar que una gran parte de las personas que separan la basura o los residuos ponen en práctica su posterior venta como una acción común para obtener un ingreso extra; $y$ son los residentes del oriente quienes demandan la existencia de un mayor número de centros de acopio para aprovechar esta opción, toda vez que el nivel de ingresos para un amplio sector es limitado.

$Y$ en referencia al nivel de ingresos, la información disponible confirma la presencia de brechas entre lo que se obtiene mensualmente en los hogares y que las percepciones extras pueden equivaler a una cifra mayor que 8000 pesos, según los datos recogidos. En suma, cabe precisar que los ingresos medios de la población equivalieron a \$5022.07 pesos al mes y que la desviación típica se ubicó en \$2 209.34 pesos mensuales (gráfica 4).

Gráfica 4. INGRESOS NETOS MENSUALES POR HOGAR

\begin{tabular}{|l|l|l|}
\hline \multirow{2}{*}{ Media } & Válidos & 530 \\
\cline { 2 - 3 } & Perdidos & 0 \\
\hline Mediana & 5022.07 \\
\hline Moda & 4500.00 \\
\hline Desv. típ. & 4000 \\
\hline Varianza & 2209.340 \\
\hline
\end{tabular}

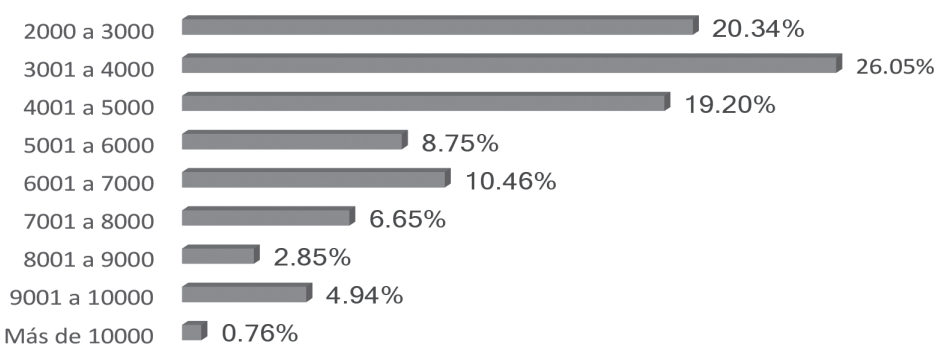

Fuente: Elaboración propia con base en el levantamiento en las aulas.

En particular, el mayor peso de ingresos netos declarados por los participantes se ubicaba en la franja de 2000 a 5000 pesos mensuales. Por el contrario, la minoría, los de mayores ingresos, representa solo $0.76 \%$ de la población encuestada, quienes declararon acceder a niveles de percepciones mensuales mayores de \$10000 pesos. 


\section{Características de los residuos generados}

En el segundo rubro de los ítems del cuestionario se incluyeron preguntas para conocer las percepciones de la población encuestada con respecto a la limpieza de la ciudad de forma que se proporcionaran datos para relacionarlos con ese servicio urbano asumido por PASA.

Adicionalmente, esta batería de indicadores se asoció también con los aspectos generales del manejo de los residuos sólidos domiciliarios que reflejaron las experiencias propias de las personas cuestionadas. Pero, antes de mostrar los resultados deseamos aclarar que en algunos casos se apuntan consideraciones relacionadas.

Según Cuoto et al. (2012), la Dirección de Limpia del municipio de Juárez declaraba dar cumplimiento a una cobertura de $94 \%$ de la ciudad para la recolección de los residuos sólidos municipales. En este caso, las personas participantes declararon vivir en 155 colonias ubicadas ya sea en el oriente o poniente de Ciudad Juárez. Se obtuvo que $46 \%$ de la gente interrogada declaró percibir la ciudad como una urbe sucia y en el caso contrario se ubicó un $44 \%$ al indicar que la observaba muy limpia (cuadro 5). El Io \% restante señaló mirarla muy sucia. Ello sugiere que la población considera que la empresa concesionaria no cumple a cabalidad con el aseo urbano, por lo que el servicio de recolección no ha logrado una eficiencia suficiente.

Cuadro 5. Percepción de la ciudad

SEGÚN CONDICIONES DE LIMPIEZA O SUCIEDAD

\begin{tabular}{|l|l|l|l|l|l|}
\hline Condición & Porcentaje & Condición & Porcentaje & Condición & Porcentaje \\
\hline Urbe sucia & $46 \%$ & $\begin{array}{l}\text { Urbe muy } \\
\text { limpia }\end{array}$ & $44 \%$ & $\begin{array}{l}\text { Urbe muy } \\
\text { sucia }\end{array}$ & Io \% \\
\hline
\end{tabular}

Fuente: Elaboración propia con los datos obtenidos en el trabajo de campo.

El hecho de reconocer que los índices de cobertura en recolección de RS por parte de PASA han sido altos de 2006 a 2014 (PASA 2013 y Gobierno Municipal de Juárez, 20II y 20I4) implica no negar la existencia de sectores de la ciudad que no necesariamente cuentan con este servicio, por lo que existen zonas en que se ven obligados a recurrir a otras formas para eliminar los residuos, tales como enterrarlos, quemarlos o tirarlos en lotes baldíos, propiciando problemas y consecuencias en materia ambiental y de salud. 
Una inquietud adicional se enfocaba a conocer la opinión de la gente en cuanto a en quién recae la responsabilidad de reducir la cantidad de residuos en la ciudad. En las respuestas se obtuvo una preponderancia en el deslinde de corresponsabilidades, ya que mientras que la tercera parte mencionó que le toca a los ciudadanos, casi cuatro de cada io dijeron que era obligación del gobierno. Uno de cada Io opinó que toca a la iniciativa privada y $16 \%$ consideró que debía ser responsabilidad de todos, léase ciudadanos, iniciativa privada y gobierno (cuadro 6).

\section{Cuadro 6. Actores responsables de la reducción}

DE LOS RESIDUOS GENERADOS

\begin{tabular}{|l|l|l|l|l|l|l|l|}
\hline Responsable & $\%$ & Responsable & $\%$ & Responsable & $\%$ & Responsable & $\%$ \\
\hline Ciudadanos & $33 \%$ & Gobierno & $39 \%$ & Iniciativa privada & I2 \% & Todos & I6\% \\
\hline
\end{tabular}

Fuente: Elaboración propia con los datos obtenidos en el trabajo de campo.

De acuerdo con la teoría, es interesante resaltar que $66 \%$ de los encuestados respondieron que no solo era obligación del gobierno reducir la generación de basura domiciliaria, sino de los tres entes sociales (gobierno, iniciativa privada y sociedad); lo que, siguiendo a Hafkamp (2002), implica reconocer que mientras en el "viejo régimen" de gestión de residuos el municipio había de preocuparse como único responsable por la salud pública y atender todo lo relacionado con la eliminación de los residuos sin importar las implicaciones de contaminación ambiental y escasas acciones de control en la disposición final, en el nuevo régimen corresponde a todos asumir acciones para minimizar los riesgos medioambientales y los propios del sector público y privado.

Una pregunta interesante del cuestionario requirió indagar o explorar si la gente tenía claro qué eran los residuos sólidos. $\mathrm{Al}$ respecto, cabe precisar que basura fue el término más común para referirse a los residuos sólidos, o sea, se les reconoce como sinónimos. En las respuestas ocurrió que poco más de la mitad del grupo de personas ( $54 \%$ ) expresó saber qué es un residuo sólido y el $46 \%$ señaló ignorarlo. $\mathrm{Y}$ del porcentaje que indicó conocer qué significaba el término de residuo, $44 \%$ no dio respuesta sobre qué es y el $56 \%$ argumentó que se refiere a basura ( $27 \%$ ), vidrio, plástico, cartón $(22 \%)$ y material reciclable (7\%).

Observado lo anterior, se consideró de gran importancia conocer las prácticas de consumo y desecho que efectuaban los habitantes de Ciudad Juárez debido al impacto que aquellas podían generar en cuanto a su reducción. 
En cuanto al material más abundante en la cantidad de basura o desecho identificado en los domicilios se obtuvo que el plástico fue predominante al representar $60 \%$ ( $30 \%$ en recipientes plástico y otro $30 \%$ en bolsas de plástico) en el conteo. En seguida se observó el aluminio, con I2 \%, que, conviene mencionar, es el de más valor en el mercado. En el caso del resto de materiales representados como basura se concentró $7 \%$ para el papel y otro 7 \% para el cartón. Los periódicos y revistas, las hojas y ramas al igual que el vidrio, la ropa o telas y electrodomésticos fueron los materiales con menor abundancia entre los residuos sólidos de los hogares (gráfica 5).

\section{Gráfica 5. Materiales con mayor presencia en la basura}

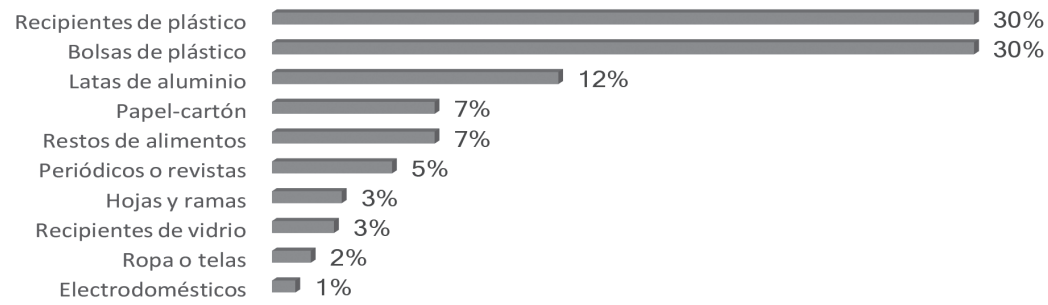

Fuente: Elaboración propia con los datos obtenidos en el trabajo de campo.

Estas condiciones invitan a reflexionar sobre la importancia de que las personas tengan conocimiento con respecto a sus patrones de consumo, según los hábitos y costumbres derivados de su cultura poblacional.

\section{Prácticas de consumo-desecho (generación, separación y reciclaje) de los informantes}

El contenido de este apartado resultó clave en cuanto a los objetivos y las inquietudes derivadas del problema de investigación en turno. No solo porque brindó señales con respecto a cuáles eran las prácticas de consumo-desecho que distinguían a la población encuestada y residente en Juárez, Chihuahua, en 2014, sino porque las variables relacionadas constituyeron los argumentos que favorecerían la definición de estrategias a favor de la minimización de generación de residuos sólidos domiciliarios. Mostramos a continuación algunos ítems y correspondientes resultados.

Por lo que corresponde a la experiencia de separar o clasificar la basura en casa, se obtuvo que 50 \% declaró que sí separaba o clasificaba sus residuos, $45 \%$ mencionó que no lo hacía y $5 \%$ se abstuvo de responder. Por lo que respecta a los tipos de 
separación que se realizaba en los domicilios, se supo que prácticamente is de cada Ioo personas hacían una separación primaria; alrededor de 28 de cada Ioo lograba una separación básica de aluminio, plástico, cartón, desperdicios orgánicos y vidrio. Pero el resto, equivalente a $57 \%$, no tenía la costumbre de practicar la separación de la basura en su domicilio (cuadro 7 ).

\section{Tabla 7. Tipos de Separación de LOS Residuos QUE SE PRACTICAN EN LOS DOMICILIOS}

\begin{tabular}{|l|l|}
\hline Tipo de separación & Porcentaje \\
\hline Separación primaria: orgánico e inorgánico & $14.30 \%$ \\
\hline Separación básica: aluminio, plástico, cartón, desperdicios orgánicos y vidrio & $28.60 \%$ \\
\hline No contestó & $57.10 \%$ \\
\hline
\end{tabular}

Fuente: Elaboración propia con los datos obtenidos en el trabajo de campo.

Esta última cifra representa una preocupación de peso y a su vez un argumento importante, ya que al representar a casi seis de cada io personas, la mayoría, alienta la acción de diseñar estrategias que incentiven a la población a separar los residuos sólidos domiciliarios no solo porque se les asigna un valor y un precio en Latinoamérica y específicamente en México (RSU, 2OIIः I76) sino porque hay personas que tienen necesidades económicas fuertes y encuentran en los desechos un beneficio económico donde, en los hechos, la práctica de la separación se convierte en un trabajo que paradójicamente permite que se reduzcan radicalmente los costos de producción en el procesamiento de metales, botellas de pet, cartón u otros materiales valorizables.

Es por ello que al porcentaje de personas que indicó manejar una lógica de separación en la fuente de generación, se le preguntó cuáles materiales no entregaba al camión recolector. En el cuadro 6 se tiene que el material menos tirado de desecho por orden de importancia era el aluminio, seguido de cerca por los plásticos, la ropa o telas, los residuos orgánicos (entendido como restos de alimentos), el vidrio, el papel-cartón, los periódicos y revistas, y finalmente la reserva de hojas y ramas en menor cuantía. En términos detallados, los resultados obtenidos reflejaron lo siguiente:

+ Del aluminio $86 \%$ se vendía y $14 \%$ se reutilizaba;

- De los plásticos, $73 \%$ se vendía, $26 \%$ se reutilizaba y i \% se utilizaba como fuente de calefacción. 
- Por lo que corresponde a la ropa o tela, se obtuvo que 6 I \% la vendían, $36 \%$ la reutilizaban y $3 \%$ la quemaban.

- En cuanto a los residuos orgánicos, resultó que 4I\% lo destinaban para alimentar animales, $29 \%$ como abono para la tierra, $24 \%$ lo procesaban en composta y solo $6 \%$ lo destinaban a la venta.

- El vidrio resultó ser el material que más se reutilizaba de acuerdo con las respuestas emitidas, por $54 \%$, y solo $46 \%$ lo destinaban para su venta.

- En el caso del papel y el cartón se destinaba a su venta 46\%,28\% lo reutilizaban y $26 \%$ lo quemaban.

+ Por lo que compete a los periódicos y revistas, 42 \% las vendían, $35 \%$ las reutilizaban y $22 \%$ las quemaban.

- Finalmente, $84 \%$ de los encuestados utilizaban las ramas y hojas como abono para la tierra y $16 \%$ optaba por quemarlas.

En suma, se apreció que las personas no necesariamente disponían de prácticas homogéneas en cuanto a la disposición final de los residuos separados. Sin embargo, la buena noticia de este balance es que estas prácticas son relativamente fáciles de replicar al explicarle a la gente los beneficios e impactos positivos que pueden desprenderse a partir de disponer de una "cultura a favor de la separación y la reutilización de los materiales".

De esta forma, al reconocer que $45 \%$ de las personas no realizaban prácticas de separación en la fuente, se consideró pertinente hacer preguntas relacionadas con propuestas que convendrían accionar en favor de aplicar medidas, léase sanciones o incentivos, que favorecieran buenas prácticas en términos del consumo y desecho de los RSD.

En síntesis, los ciudadanos sugirieron algunas medidas a través de las cuales podrían aplicarse o no sanciones para estimular o evitar la separación de la basura desde los domicilios. En el caso de las respuestas negativas, donde enfocamos la atención, se obtuvo que las personas indicaron no estar de acuerdo en la aplicación de sanciones a quienes no separaran la basura debido a que en primer lugar sería otra forma de recaudar dinero de los ciudadanos, en segundo lugar porque no se lograría o tendría garantía que las personas separasen los residuos con esta medida y en tercer lugar porque el gobierno, en tanto agente estratégico, no ponía el ejemplo en esta tarea (gráfica 6). 


\section{Gráfica 6. Razones asumidas para no SANCionar}

\section{LA SEPARACIÓN DE LA BASURA}

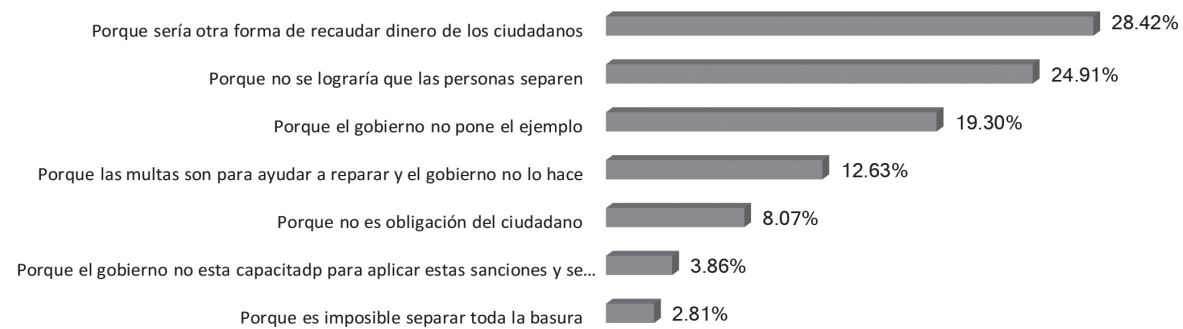

Fuente: Elaboración propia con los datos obtenidos en el trabajo de campo.

En cambio, en el caso de las personas que estuvieron de acuerdo en sancionar a quienes no separaran la basura, se refirió que entre las medidas aceptables podrían considerarse: i) cobrar tarifas directas según el nivel de ingresos (37\%), ii) cobrar el servicio de recolección a quienes incumplieran la ley en el impuesto predial (36\%) $y$, iii) asignar multas proporcionales a la cantidad de basura generada por hogar medidos según los kilogramos y los tipos de residuos generados, como las principales $(27 \%)$.

Finalmente, en el caso de la indagación realizada con respecto a qué estaría dispuesta la gente a hacer para evitar la generación de tanta basura, previa separación, se encontró lo siguiente: la mayoría, equivalente a 71\%, indicó estar dispuesta a realizar acciones para modificar sus prácticas de desecho y consumo a cambio ya sea de contar con un centro de acopio o reciclaje cerca de casa, recibir dinero a cambio o recibir vales de despensa, entre otras propuestas (gráfica 7).

\section{Gráfica 7. Acciones posibles para reducir y Separar la basura}

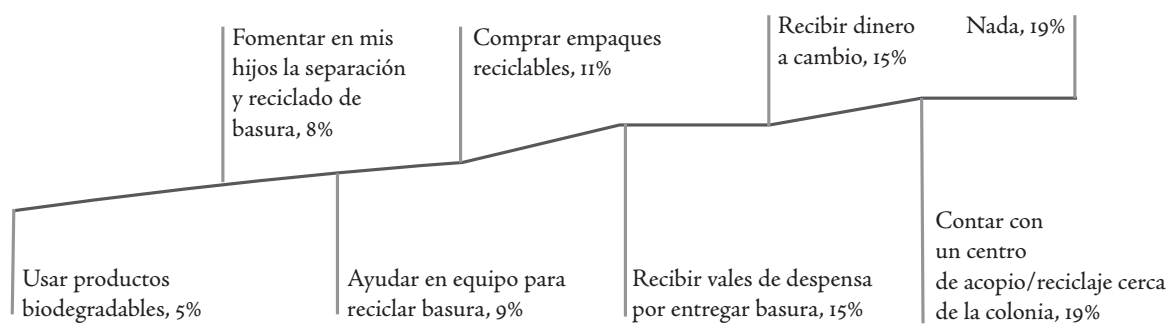

Fuente: Elaboración propia con los datos obtenidos en el trabajo de campo. 
Casi $20 \%$ del total declaró una disposición nula para separar. Es decir, una de cada cinco personas mostró indiferencia para minimizar su producción de residuos domiciliaria. El hecho de no estar dispuesto o dispuesta a separar tal vez sea comprensible dado que en Juárez dicha práctica no es una exigencia u obligatoriedad.

No obstante, al indagar a través de tablas de contingencia cuáles personas son más propensas a separar la basura en casa según el género, la edad y el nivel de escolaridad se encontró lo siguiente:

I. Del porcentaje de personas que sí separan la basura en casa (47.6\%), las mujeres tienden a representar 58.1\% y los hombres 47.6\%. De las personas que no separan los residuos dentro de casa, equivalentes al $47.6 \%$ del total, se tiene que los hombres representan $52.4 \%$ y las mujeres $49.1 \%$,

2. En el caso de la edad, las personas de 30 a 44 años cumplidos son más propensas a separar la basura en casa (34.I\%), luego las de 15 a 29 años (33.1 \%) y finalmente las que indicaron tener 45 años o más (30.8\%). Y se tiene un comportamiento similar en el caso de quienes no separan los RSD. El primer lugar lo ocupa el grupo de 30 a 44 años; el segundo, el grupo de 15 a 29 años, y la tercera posición es del grupo de 45 años o más. En síntesis, los porcentajes representativos de cada grupo son $41.4 \%, 31.4 \%$ y $27.2 \%$, respectivamente.

3. En el caso del nivel de escolaridad se obtuvo que los que contaban con estudios de preparatoria son los que tienden en mayor proporción a separar la basura en casa (37.6\%). En segundo sitio se ubica el grupo con universidad trunca $(20.5 \%)$ y el tercer lugar corresponde a aquellos con nivel secundaria (18.3\%). E igual ocurre con aquellos que no tienen la cultura de separar los RSD. Los primeros tres lugares son ocupados por aquellos con preparatoria, universidad trunca o nivel secundaria al representar el $78.2 \%$ del total.

En síntesis, puede concluirse que los resultados obtenidos sí proporcionan información enriquecedora para diseñar estrategias que conduzcan a que la población que reside en Ciudad Juárez se vea incentivada a atender buenas prácticas para lograr la minimización de los residuos sólidos en los domicilios a partir de asumir la separación. Sin embargo, las estrategias que se promuevan desde las diversas esferas (privadas, públicas, educativas) deben prestar atención al hecho de que las medidas habrán de focalizarse por grupos de población y zona de residencia para que el proyecto tenga mayor probabilidad de resultar exitoso. Así, adquiere sentido listar algunas recomendaciones y consideraciones finales. 


\section{Consideraciones finales y algunas recomendaciones}

El tratamiento de los residuos sólidos es uno de los más grandes desafíos que deben enfrentar los gobiernos de las ciudades del mundo en el siglo xxi. En coincidencia con Martínez (2015), no es desconocido que tanto en las actividades domésticas como en las industriales se utilizan bienes y materias primas para el consumo y la producción de otros bienes, dando lugar a residuos que la naturaleza no puede reabsorber fácilmente por lo que constituyen una amenaza de destrucción del ambiente.

La acción de tomar conciencia de que el volumen de desperdicios generados en las áreas urbanas, y principalmente en Ciudad Juárez, se ha convertido en una cuestión muy preocupante para la conservación del medio ambiente por la magnitud de las cantidades de residuos y sus impactos, demanda realizar investigaciones con miras a encauzar $y$ tomar con seriedad aquellas medidas que contribuyan a incentivar no solo la separación de los residuos (sin mezclarse) o la atención de procesos de reciclaje y re-uso adecuados sino observar los mecanismos que han de conducir la reducción de los costos derivados de las prácticas de consumo-desecho irracional que protagoniza un amplio número de consumidores.

Los resultados obtenidos en el trabajo de campo en Ciudad Juárez llevan a reflexionar que para reducir los volúmenes de los residuos sólidos conviene realizar recomendaciones y propuestas de buenas prácticas de manera focalizada, ya sea considerando categorías de la población o zonas de residencia sin concebir que todas las medidas habrán de dirigirse a una sociedad en su totalidad.

En esta lógica, una aportación importante que propone esta investigación consiste en reconocer que el consumo masivo se advierte como un elemento nocivo para el medio ambiente y para el desarrollo sostenible.

Por ello, es conveniente y recomendable que los distintos actores corresponsables de la generación de residuos (hogares, gobierno, empresas, concesionarias) tomen nota de esta problemática para minimizar la cantidad de los desechos y atender prácticas que den cumplimiento a las $3 \mathrm{R}$ en favor del bienestar de las generaciones actuales y de las futuras.

Por lo anterior, la oportunidad de diseñar estrategias y políticas a favor de la salud y la toma de conciencia de los residentes de Juárez representa una medida para incentivar no solo la participación ciudadana sino analizar diversas opciones que incentiven o estimulen la creación de empresas innovadoras a favor del sistema municipal del reciclaje como la integración de un programa de separación de residuos cuyos preceptos básicos consistan en promover buenas prácticas diferenciadas por grupos de población. 
Por lo anterior, la necesidad de promover esquemas y programas de educación ambiental sobre el manejo de los residuos sólidos domiciliarios se propone como una actividad prioritaria y atinada. Ello implica formular indicadores adecuados que permitan monitorear los estatus para cada país y región conforme a los parámetros dictados por organismos supranacionales como la Organización Panamericana de la Salud a través de sus informes (ops, 200I). Confiemos en que podamos involucrarnos en estos procesos y ver qué ocurre en los próximos meses y en los próximos años.

\section{Bibliografía}

Ariza, Marina. s.f."La urbanización en México en el último cuarto del siglo xx": Avance de investigación. México: Instituto de Investigaciones Sociales, Universidad Nacional Autónoma de México. Consultado: http:// es.scribd.com/doc/38655769/Reporte-de-investigacion2

Banco Bilbao Vizcaya (1993), Diccionario de la Naturaleza, España: Banco Bilbao-Vizcaya.

Bernache Pérez, Gerardo (2007), Cuando la basura nos alcance: el impacto de la degradación ambiental. México: Centro de Investigaciones y Estudios Superiores en Antropología Social (ciesas).

Bernache Pérez, Gerardo; Miguel Bazdresch Parada, José Luis Cuéllar y Francisco Moreno (1998), Basura y metrópoli. Gestión social y pública de los residuos municipales en la zona metropolitana de Guadalajara, México: Universidad de Guadalajara Editorial/Centro de Investigaciones y Estudios Superiores en Antropología Social-Occidente/Universidad Jesuita de Guadalajara/Colegio de Jalisco.

Brown Salazar, Doreen (coord). (2003), Guía para el Manejo de los Residuos Sólidos en Municipales. Enfoque: Centroamérica, El Salvador: Agencia de Estados Unidos para el Desarrollo Internacional/Programa Ambiental Regional para América Latina/Sistemas de Gestión para el Medio Ambiente.

Buenrostro, Otoniel (200I), Los residuos sólidos municipales. Perspectivas desde la investigación multidisciplinaria, México: Editorial U.

Buenrostro, Otoniel y Gerardo Bocco (2003), "Solid waste management in minicipalities in México: goals and perspectives", Resources, Conservation E Recycling, 39, pp. 25I-263.

Cuoto Benítez, Ismael (2008), Evaluación de la Gestión Integral de Residuos Sólidos Urbanos en la Frontera Norte: los casos de Juárez, Reynosa y Tijuana, tesis de maestría inédita, México: Colegio de la Frontera Norte. 
Cuoto Benítez, Ismael, Alberto Hernández y Cecilia Sarabia (20I2),"La gestión integral de los residuos sólidos urbanos en Juárez: lecciones innovadoras para otros municipios", Revista Pueblos y fronteras digital, 7(13), junio-noviembre, pp. 178-209.

Deffis Caso, Armando (1994), La basura es la solución, México: editorial Árbol. De la Cruz, F. (2008), Casi todo lo que compras lo tiras. Proyecto de reflexiones sobre el consumo cotidiano y nuestra relación con la basura, en <http://www. basurama.org/bo8_casi-todo-lo-que-compras-lo-tiras.htm $>$ [consulta: $\mathrm{I3} / \mathrm{IO} / 2 \mathrm{OI} 3]$.

El Diario (2014), Recortan recolección de basura y amplían concesión a PASA, en <http://diario.mx/Local/2014-04-24_ef7751e7/recortan-recoleccion-de-basura-y-amplian-concesion-a-pasa/ > [consulta: 25/04/2014].

Esteban, María Teresa (199I), Las evaluaciones del impacto ambiental, Madrid: Centro Internacional de Formación en Ciencias Ambientales (CIFCA). Gobierno Municipal de Juárez (20II), Información General del Municipio de Juárez, en <http://www.juarez.gob.mx> [consulta: 23/05/2015].

Gobierno Municipal de Juárez (2014), Dirección de Limpia, en <http://www. juarez.gob.mx/bienvenido/> [consulta: 3/03/2014].

Hafkamp, Win (2002), Comparison of National Solid Waste Regimes in Trajectories of Chang, en N. Buclet (ed.), Municipal Waste Management in Europe, European Policy between Harmonisation and Subsidiarity, Kluwer Academic Publishers, pp. 7-26.

Heroica Ciudad Juárez. Secretaría del Ayuntamiento (2014), Oficio número REG/ARR/580, en <http://www.juarez.gob.mx/20I5cf/transparencia/ docs.php?file $=13612830>$ [consulta: 20/07/2017].

Huelstrunk, Wilfried (2008), ¿Qué es el programa de competitividad y medio ambiente?" Ambientico. Revista mensual sobre la actualidad ambiental. Por una inmediata gestión integral de los resiudos sólidos, 178, pp. 3-4.

Instituto Mexicano de la Competitividad (imco) (20I4), Índice de Competitividad Estatal 2014: Las reformas y los estados. Obtenido del < http:// imco.org.mx/indices/indice-de-competitividad-estatal-20I4-las-reformas-y-los-estados/> [consulta: 19/03/2014]

Instituto Municipal de Planeación de Ciudad Juárez (2005), Cartografía de centros escolares en Ciudad Juárez, Chibuabua. Ciclo escolar 2004-2005, Ciudad Juárez: Chihuahua.

Instituto Nacional de Ecología (INE) (1999), "Manejo Integral de los Residuos Sólidos", en Minimización y manejo ambiental de los residuos sólidos 
no. 3, México: Secretaría de Medio Ambiente y Recursos Naturales (SEMARNaT)

Instituto Nacional de Estadística y Geografía (INEGI) (20I0), Chibuabua, compendio censal del siglo XX, México: INEGI.

Jiménez Martínez, Nancy Merary (2015),"La gestión integral de residuos sólidos urbanos en México: entre intención y realidad", Letras Verdes. Revista Latinoamericana de Estudios Socioambientales, pp. 29-56.

Ley de Equilibrio Ecológico y la Protección al Ambiente (2014), Ley de Equilibrio Ecológico y la Protección al Ambiente, México: Diario Oficial de la Federación [última reforma].

Ley General para la Prevención y Gestión Integral de los Residuos Sólidos (LGPGIR) (20I4), Artículo 5, Fracción XXXIII.

Naciones Unidas (2017), División de población de las Naciones Unidas, en <http:// www.un.org/es/sections/issues-depth/population/index.html $>$ [consulta: 20/07/2017].

Organización para la cooperación y el Desarrollo Económico (oECD) (2014), OECD Factbook 2014: Economic, Environmental and Social Statistics, en $<$ http://dx.doi.org/10.1787/factbook-2014-en>.

Ojeda Benitez, Sara; Carolina Armijo de la Vega y María Elizabeth RamírezBarreto (2000), "The potential for recycling household waste: a case study from Mexicali, México", Environment and Urbanization, I2.

Organización Panamericana de la Salud (ops) (200I), Indicadores para el gerenciamiento del servicio de limpieza pública, Lima.

Packard, Vance (1960), The Waste Makers, Nueva York: David McKay publishing. Promotora Ambiental S.A. de C.V. (PASA) (2013), Reporte anual de Promotora Ambiental S.A. de C.V., en <https://www.pasa.mx/pdf/otros_reportes/ReporteAnualcnBv2013.pdf> [consulta: 23/04/2014].

Programa de las Naciones Unidas para el Medio Ambiente (PNuma) y Secretaría de Medio Ambiente y Recursos Naturales (semarnat) (2004), Perspectivas del medio ambiente en México. geo México 2004, México.

pnuma/semarnat-Programa 2i (1992), Gestión ecológicamente racional de los desechos sólidos y cuestiones relacionadas con las aguas cloacales, en <http://www.un.org/spanish/esa/sustdev/agenda2I/agenda2Ispchapter2I.htm $>$ [consulta: 18/03/2013].

Ramírez Saíz, Juan Manuel (1998), ¿Cómo gobiernan Guadalajara? Demandas ciudadanas y respuestas de los ayuntamientos, México: Miguel Ángel Porrúa.

Ramírez, Tulio (1999), Cómo hacer un proyecto de investigación, Caracas: Panapo. 
Restrepo, Iván y David Phillips (1985), La basura, consumo y desperdicio en el Distrito Federal, México: Centro de Ecodesarrollo.

Rodríguez, Ana Lucía (2008), Gestión Local e intergubernamental de los residuos sólidos urbanos. Una evaluación de las "buenas prácticas" en los municipios mexicanos, tesis de maestría inédita, México: El Colegio de la Frontera Norte, Centro de Investigación Científica y Educación Superior de Ensenada. Rubio Salas, Rodolfo (2005), “Características sociodemográficas”, en L. E. Cervera Gómez, Diagnóstico geo-socioeconómico de Ciudad Juárez y su sociedad, Mexico: El Colegio de la Frontera Norte-Instituto Nacional de las Mujeres, pp. 38-65.

Residuos Sólidos Urbanos (rsu) (20iI), Residuos Sólidos Urbanos. Baura y espacio público en Latinoamérica, España: Delirio.

Sabino, Carlos (1992), El proceso de investigación, Caracas: Editorial Panapo.

Salgado López, Juana Amalia (2012),"Residuos sólidos: percepción y factores que facilitan su separación en el hogar. El caso de estudio de dos unidades habitacionales de Tlalpan", Quivera, pp. 9I-II2

Sangronis Padrón, Joel (2015), Ecologia politica y capitalismo, en <http://www. ecoportal.net/TemasEspeciales/Politica/ecologia_politica_y_capitalismo $>$ [consulta: 27/04/2015].

Seóanez Calvo, Mariano (2000), Tratado de reciclado y recuperación de productos de los residuos, Madrid: Mundi-Prensa.

Secretaría de Medio Ambiente y Recursos Naturales (Semarnat) (20I2a). Informe de la situación del medio ambiente en México. Compendio de estadísticas ambientales. Indicadores clave $y$ de desempeño ambiental. Edición 2012. SNIARN. Estados Unidos Mexicanos en <http://appsi.semarnat.gob.mx/ dgeia/informe_I2/o7_residuos/cap7_I.html > [consulta: 24/05/2017]. Secretaría de Medio Ambiente y Recursos Naturales (Semarnat) (2012b), Capitulo 7. Residuos. Informe 2012, en <http://appsi.semarnat.gob.mx/dgeia/ informe_2008_ing/pdf/cap_7_residuos.pdf> [consulta: 26/05/2017].

Tejada Cota, Daniela (2013), Manejo de residuos sólidos urbanos en la Ciudad de la Paz, B.C.S.: estrategias para su gestión y recomendaciones para el desarrollo sustentable, tesis de maestría inédita, Centro de Investigaciones Biológicas del Noroeste.

Trejo, Rodolfo (1994), Procesamiento de la basura urbana, México: Trillas.

United Nations Environment Programme (UNEP) (2015), Global Waste Management Outlook, Austria: Unep/The International Solid Waste Association (ISWA). 
Villalpando Navarrete, Noemí (20II), Gestión de los residuos sólidos urbanos: enfoque desde el desarrollo sustentable y género, tesis de maestría inédita, México: Universidad Autónoma de Ciudad Juárez.

\section{RESÚMENES CURRICULARES}

Myrna Limas Hernández es doctora en Integración y Desarrollo Económico. Profesora titular de tiempo completo adscrita al Departamento de Ciencias Sociales de la Universidad Autónoma de Ciudad Juárez. Líneas de investigación: Estudios del desarrollo, Estudios de Género, Violencia, Grupos vulnerables. Obras recientes: "Mujeres y hombres en el desarrollo: debates y (des)encuentros que descifrar desde la perspectiva de género", en Ignacio Rodríguez y Paulina Sanahueza (eds.), Estudios del desarrollo: enfoques, instrumentos de medición y trabajos empíricos, Temuco, Chile, Universidad de la Frontera, pp. 39-8I; en coautoría con Reyna Rodríguez, 2017, "El análisis de las diferencias salariales y discriminación por género por áreas profesionales en México, abordado desde un enfoque regional, 2015", Estudios Sociales, $27(49)$, enero-junio, entre otras.

Janette Eréndira Blanco Romero es maestra en Ciencias Sociales para el Diseño de Políticas Públicas por la Universidad Autónoma de Ciudad Juárez. Líneas de investigación: Problemáticas de la basura, Desarrollo sustentable. Línea de investigación: problemáticas de la basura y desarrollo sustentable. Obras recientes: 2015, Análisis de las prácticas de consumo-desecho (generación, separación y reciclaje) de los residuos sólidos domiciliarios en Ciudad Juárez, 2010 al 2014, tesis de maestría, Ciudad Juárez, Chihuahua, Universidad Autónoma de Ciudad Juárez.; 20I4,"Finalidades de la sustentabilidad ambiental: una búsqueda deseable para el desarrollo en México", en Isaac Sánchez Juárez (coord.) Reflexiones Sobre Sociedad y Desarrollo en México, $<$ Lulu.com $\rangle,<$ file:///C:/Users/User/Downloads/fulltext_stamped.pdf $\rangle$.

Citar como: Limas Hernández, Myrna y Blanco Romero, Janette Eréndira (2017),"Prácticas de consumo-desecho de residuos sólidos domiciliarios en Ciudad Juárez en 2014", Iztapalapa. Revista de Ciencias Sociales y Humanidades, núm. 83, año 38, julio-diciembre de 20I7, ISSNः 2007-9176; pp. 97-I32. Disponible en $<$ http://revistaiztapalapa.izt.uam.mx/index.php/izt/issue/archive $>$. 